\title{
What do females really dream of? An individual-differences perspective on determining how narrative identity affects types of life projects and the ways of telling them
}

\author{
Izabela Kaźmierczak ${ }^{1}$ (D) Michał Szulawski ${ }^{1} \cdot$ Agnieszka Masłowiecka $^{2} \cdot$ Mariusz Zięba $^{3}$
}

Accepted: 12 April 2021 / Published online: 22 April 2021

(C) The Author(s) 2021

\begin{abstract}
This article presents the findings of a study on life projects (LPs) created by adult females. It aims to show the specifics of future plans and of ideas on aspects of narrative identity in order to extend the existing literature. The study revealed the broad spectrum of LPs, with the most common categories related to study and work, regardless of the narrative identity incorporated into the study. However, separately taken, motives of agency and communion turned out to show some visible differences within the other types of LPs. The adoption of the identity development construct showed the specific meaning that projects had for each subgroup of narrators, who were distinguished based on the identity maturation level. In consequence, it exposed both content and formal aspects of LPs that appeared to differentiate and be characteristic for the next stages of maturity in the surveyed sample.
\end{abstract}

Keywords Life projects · Narrative identity $\cdot$ Identity development $\cdot$ Females

It has been argued that early adulthood is the beginning of a new life. It is also the time when people are getting to know themselves better (Turner \& Helms, 1995) and can pursue their chosen lifestyle and determine their place in the surrounding world. Entering the period of adulthood places the individuals in situations where they need to revise their identity (Erikson, 1950, 1968). It is done by reworking childhood identifications into a bigger, consistent and self-determined set of goals, ideals and values (Lapsley \& Hardy, 2017; Schwartz, 2001). Levinson (1978) called the process forming a Dream, an individual myth, a sometimes underdeveloped vision giving reason and meaning for an individual's life. According to McAdams (2008b), a life project (LP) is a set of goals that a person has been working on and/or has an intention to work on in the future. Personal goals are flexible cognitive

Izabela Kaźmierczak ikazmierczak@aps.edu.pl

1 Institute of Psychology, The Maria Grzegorzewska University, Szczę́liwicka 40, 02-353 Warsaw, Poland

2 Faculty of Pedagogy and Psychology, University of Białystok, Bialystok, Poland

3 Faculty of Psychology and Law, University of Social Sciences and Humanities, Campus in Poznań, Poznań, Poland orientations toward doing something and being in the world (McGregor et al., 2006). They explain who we hope to be in the nearest future.

\section{Types of Life Projects Amongst Women}

Conducting his research over the course of adult development, Levinson (1978), in his work, The Seasons of a Man's Life, showed that men's dreams most often appeared to be occupational in nature. Although this finding was based on a sample of 40 males aged from 35 to 45 years, it was considered to providing a distinctive perspective on adult personality, and showed that females passed through similar stages as well. Levinson never directly stated that there were any variations in the adult development between the sexes. As a matter of fact, he amplified the theoretical implications of his earlier findings (Levinson, 1986) in The Seasons of a Woman's Life, published posthumously (Levinson, 1996). It discussed how 45 females (aged 35 to 45) whom he also had interviewed, went through an almost identical sequence of age-related developmental stages as the males.

However, Kittrell (1998) noticed that the answers presented in The Seasons of a Man's Life revealed that the majority of men in their late teens and early 20s developed Dreams of primarily an occupational nature. Apparently, a professional 
career was the crucial component of men's identity formation. At the same time, interviews in The Seasons of a Woman's Life suggested a lack of vitalising career Dreams among Levinson's female subjects, even among the career women, during the same period. What is more, unlike the majority of males, most of them failed to form a Dream by the end of the adolescent-adult transition stage (Early Adult Transition 1723, Levinson, 1978). The closest thing to Dreams were their fantasies about marriage and becoming full-time homemakers or balancing homemaking with working in a less traditional marriage. Not until the female interviewees turned 30 (Age Thirty Transitions 28-33, Levinson, 1978) did they develop individualistic or occupational Dreams, which was often a decade later than males (Kittrell, 1998). What is more, the formation of their Dreams was complicated. The acceptance of female roles and having the main responsibility for family care created internal conflicts, which were rarely experienced by the males, whose Dreams tended to be devoted to one subject and be more goal oriented (Kittrell, 1998). Moskal (2020) also showed that young females faced great challenges in developing professional careers, curtailed by family and social pressures.

Therefore, if females create and realize their Dreams later than males and the process is complicated, there is a need to explore their varied developmental paths and their unique conflicts between the needs of relational and individualistic nature. Hence, this article presents the findings of a study concerned with the LPs of adult females; its aim is to show the specifics of the future plans and ideas generated by females two decades after Levinson's last work. We assume that, during adulthood, the developmental tasks of females may be different from those of males from Levinson's research $(1978,1986,1996)$, or even from those that were found in Kittrell's exploration (Kittrell, 1998).

\section{The Role of Narrative Identity in Constructing Life Projects}

Because we assume there is a broad spectrum of ways in which we might construct our LPs, it justifies raising the question of what factors determine the types of generated projects and the ways of telling these stories by females (for example, length of LP scripts, the number of threads and coherence). Some light is thrown on these questions by the narrative identity construct (McAdams \& McLean, 2013). People specifically create and internalize life stories (McAdams, 2001) in order to integrate not only the reconstructed past, but also the imagined future. In this way, narrative identity provides life with the sense of integration, reason and meaning (Bauer et al., 2006; McAdams, 2008b). Among the most significant individual differences between people are those concerning structure and content of their narrative identities (McAdams
\& McLean, 2013). In consequence, their narratives may be compared and contrasted with respect to the importance of themes such as agency and communion (McAdams et al., 1996). They are the two universal content dimensions in life stories that have often been described in the literature (Bakan, 1966; Woike, 1995). Agency includes a wide array of motivational ideas concerning the concepts of might, power, expansion, mastery, control, dominance, achievement, autonomy and separation, whereas communion covers motivational ideas that include interpersonal connections - close relationships, such as love, friendship, affiliation, intimacy, sharing, belonging, care and nurturance (McAdams et al., 1996).

Although agency, with all its motifs, is an unquestionable goal of individual development (e.g., Labouvie-Vief, 1994), it is argued that being both independent and able to generate mutually satisfying relationships constitutes a more advanced level of maturation (Guisinger \& Blatt, 1994). What is more, Gutmann (1994) and Labouvie-Vief (1994) also suggest that as age and maturation increase, the dialectic friction between agency and communion may change, leading to a more level relationship between them. Hence, we assume that having the combination of strong communion and agency within a person constitutes a manifestation of a higher level of identity development compared to being strong only in either communion or agency.

The aforementioned assumptions suggest the following questions: Are the identity development phases associated with the types of LPs; also, are they related to the way the stories are told by females? To answer this, we sought to discover patterns that distinguish the LPs reported by females with a different constellation of themes of agency and communion.

\section{Motivation to Construct and Realise Life Projects}

Agency and communion themes of LPs can manifest themselves in looking for environments that satisfy basic psychological needs (Deci \& Ryan, 2000; Ryan \& Deci, 2017). Selfdetermination theory's (SDT) motivational perspective on development describes human beings as having three universal needs - autonomy, competence and relatedness - which serve as social nutrients for supporting the process of internalisation of goals, values and behavioural regulations from external sources and integrating them into an individual's own identity (Ryan \& Deci, 2017).

The theme of agency should be linked with motivation of looking for situations and environments that satisfy (and not frustrate) the needs for autonomy and competence. Autonomy satisfaction occurs when one experiences a sense of volition, psychological freedom and authorship in one's thinking, acting and feeling, while autonomy frustration denotes a feeling 
of lack of control, pressure and conflict. Competence, on the other hand, involves feeling that one is effective and developing, while competence frustration denotes a feeling of failure and lack of development. The communion themes, however, could be connected with motivation of looking for situations and environments that satisfy relatedness. Relatedness involves feeling meaningfully and being warmly connected to others, while relatedness frustration denotes feelings of social alienation and loneliness (Deci \& Ryan, 2000; Ryan \& Deci, 2017). Some authors suggest that SDT differentiation of the three basic psychological needs lacks the need for safety, which also may affect an individual's identity development (López-Rodríguez \& Hidalgo, 2014).

Research has shown that the themes of agency and communion are related, on one hand, to such operant measures of personal striving as motivation and, on the other hand, to respondent measures of needs (McAdams et al., 1996). Total communion of all narratives was positively associated with motivation for intimacy, personal strivings for warm and close relationships and needs for affiliation and nurturance. Total agency was correlated with motivation for achievement and power, personal striving to be successful, and the need for achievement and supremacy (McAdams et al., 1996). In turn, McGregor and Little (1998) found that agentic participants were happiest if others supported their goals, whereas communal participants were content when their goals brought them fun. Moreover, McGregor et al. (2006) also proved that there was a significant relationship with the extent to which participants' strivings and life-story identities had a social theme. Due to these correlations, we can assume the appearance of these basic psychological needs in the LPs of the interviewed women, depending on their agency and communion levels.

\section{Theoretical Framework Integrating Narrative Identity, Needs and Life Projects}

In searching for a relation between narrative identity, psychological needs and LPs, the New Big Five model proposed by McAdams and Pals (2006) was taken as the starting point of the study. It provides five broad and interrelated concepts: evolution, traits, adaptation, life narratives and culture. The model depicts personality as "(a) an individual unique variation on the general evolutionary design for human nature, expressed as a developing pattern of (b) dispositional traits (in current study: basic psychological needs), (c) characteristic adaptations (in current study: LPs), and (d) integrative life stories (in current study: key life-scene narratives), complexly and differentially situated (e) in social context and culture" (McAdams \& Pals, 2006, p. 212). Extended research has demonstrated the existence of important empirical relations between the components-means in which traits and motives, for example, are related to narrative identity (e.g., McAdams et al., 2004). Notwithstanding, still there is no evidence on how narrative identity affects LPs in the sample of females, especially when taking into account the developmental perspective.

Summing up, the aim of the study was to show the specifics of the future plans and ideas generated by females in the context of their personality development. We assumed that both the narrative identity and the identity development phases would be associated with the type of life projects and the way of telling them. We also assumed the appearance of some basic psychological needs in the life projects of the interviewed women, depending on their agency and communion levels.

\section{Method}

\section{Participants}

We collected autobiographical narratives of personally significant events and LPs from 54 White undergraduate female students. The inclusion criteria in the recruitment process were female gender and the age range that coincides with Levinson's early adulthood stage (from 22 to 45 years) to compare the current study with the original one (1996). We expanded the age range compared to Levinson's research sample (35-45 years) to be able to observe current LPs in emerging adulthood as well. In consequence, participants of ages 21 to 45 years were assessed, with a mean age of 30.50 years $(S D=7.60)$. All females received a research participation point in exchange for their participation.

\section{Measures}

Qualitative methods in the form of McAdams (2008a) lifestory technique were used for an interview. The interview began by asking the participant to describe eight key life scenes, such as a high point, low point, turning point, positive childhood memory, negative childhood memory, vivid adult memory, wisdom event, and a religious, spiritual or mystical experience. After describing the eight scenes, each participant went through a series of questions concerning challenges (life challenge, health, loss, failure/regret). For each scene, the participant was asked to tell exactly what happened in the scene, who was involved, what she was thinking and feeling at that time and what, if anything, the scene may mean in the context of the overall life story. The interview ended with future scripts (the next chapter, dreams/hopes/plans for the future, and LPs).

Life projects, the main dependant variable, were collected with a question: 'Do you have a project in life? A LP is something that you have been working on and plan to work on in 
the future chapters of your life story. The project might involve your family or your work life, or it might be a hobby, avocation or pastime. Please describe any project that you are currently working on or plan to work on in the future. Tell me what the project is, how you got involved in the project or will get involved in the project, how the project might develop and why you think this project is important for you and/or for other people" (McAdams, 2008b).

The interview took approximately one hour to complete. Each tape-recorded interview was transcribed verbatim. Coding for the themes of agency and communion focused on the first twelve key life-story and challenge scenes. Coding for LP categories and the way of telling them focused on LP scripts only. All coding was carried out by two independent, trained coders. Disagreements between them were resolved in a discussion with the active participation of a third coder, who was the most experienced in conducting qualitative analyses.

To investigate the themes of agency and communion in eight key life scenes, the study used the coding system developed by McAdams (2002), which was modified for the purpose of the study. This coding system divides agency into four categories: self-mastery, status/victory, achievement/ responsibility and empowerment. The coding system also divides communion into four categories: love/friendship, dialogue, caring/help and unity/togetherness (McAdams, 2001). If evidence exists for the theme in the key life story, the theme receives a score of positive one $(+1)$ for the corresponding story. If no evidence exists, the theme receives a score of zero (0) for that key life story. The total scores for agency and communion per key life story were then assessed, taking into account the number of themes and whether there were either singular or multiple references in key life stories showing a person as agentic or communal. In consequence, the highest possible score for agency or communion for a given scene was four (4) and the lowest score was zero (0).

As these constructs were rated on a 5-point ordered scale $(0-4)$ to reflect a greater or lesser presence of the constructs in key life stories (e.g., Lodi-Smith et al., 2009), the intraclass correlation coefficient (ICC) was chosen (Shrout \& Fleiss, $1979)$ for interrater reliability. The $\operatorname{ICC}(2, \mathrm{k})$ for the theme of agency was .81, which constitutes a very good level of agreement (Cicchetti, 1994; Orwin, 1994). The $\operatorname{ICC}(2, \mathrm{k})$ for the theme of communion was .71. The last coefficient is close to the acceptable level of reliability (.75) by ICC standards (Cicchetti, 1994; Orwin, 1994). All scores of agency and communion were averaged per participant separately by the two independent coders; the indices were then averaged between the coders and used as total scores in further analyses.

To distinguish the identity-development phases and to capture their impact on the type of LPs and the way of telling them, the sample of 54 female participants was divided into four groups based on both total agency and total communion intensity at the same time. It was done by median split. The groups were characterised by (1) both low dimensions (LowAG, Low-COM, $N=13$ ), (2) low agency and high communion (Low-AG, High-COM, $N=14$ ), (3) high agency and low communion (High-AG, Low-COM, $N=14$ ) and (4) high in both dimensions (High-AG, High-COM, $N=13$ ). The first group referred to the low level of identity development. The second and the third groups formed semi-matured identity with dominating motives of either community or agency, respectively, and the fourth group referred to the fully developed identity. All coders were blind to the presented groups.

Life project categories were identified using thematic analysis (Braun \& Clarke, 2006). This inductive approach aims to identify themes from qualitative data through iterative processes of familiarisation, coding, theme development, defining themes and reporting. To do so, we applied the multiple readings of qualitative data by an 'interpretive community' (Taylor et al., 1996) of three coders who were different regarding gender and life experiences. Given that the goal of the present investigation was also to elucidate the themes that characterise the LPs reported by the individuals with different constellations of the narrative identity, the thematic analysis was conducted not only for the whole sample but also separately for each group of participants. All coders were blind to the groups.

Apart from identifying LP categories, the way of telling the stories was assessed. It was done through such formal aspects of narratives as length of LP scripts (number of words), number of threads and coherence. Coherence was assessed referring to Linde's (1993) criteria, such as temporally ordered threads, causal relationships between them and continuity. Additionally, realism of the LPs was taken into account. It was operationalised as specific, set in time, containing an action program with some next steps and obstacle solutions and/ or the narrators were certain about their completion. Unrealistic LPs were defined as fantasies, generally containing lists of obstacles with no solutions and/or the narrators were uncertain about their completion.

\section{Statistical Analyses}

Narrative and thematic analyses were performed using MAXQDA 2020. The intraclass correlation coefficients (ICC) and descriptive and correlation (rho Spearman test) analyses were calculated using IBM SPSS Statistics 26.

\section{Results}

\section{Descriptive Information}

Three out of 54 participants declared that they did not have any current life projects in their lives; 23 participants 
generated one LP, and 28 of them spontaneously generated two or three of them. Thematic analysis showed convergence with the structure of the personal-project categories of Little and Gee (2007): work $(n=27)$, academic $(n=25)$, interpersonal $(n=15)$, intrapersonal $(n=14)$, maintenance $(n=2)$, health $(n=1)$, and leisure $(n=0)$.

With respect to narrative identity, the measures of the themes of agency $(M=1.30 ; S D=.40)$ and communion $(M=.08 ; S D=.30)$ appeared to be uncorrelated: $r_{s}=.09$; $p>.05$. Interestingly, neither agency nor communion was consistently associated with the number of LPs $(M=1.55$; $S D=.74): r_{s}=.07 ; p>.05$ and $r_{s}=.25 ; p>.05$, respectively. There was a weak correlation between age and the number of LPs: $r_{s}=.29 ; p=.05$. The older the participants were, the more LPs they generated.

\section{Data Analysis}

\section{The Impact of Agency and Communion on Telling Life-Project Stories}

Although agency and communion did not significantly correlate to the number of LPs, these characteristics appeared to differentiate the LP category. Participants with high agency generated the majority (65\%) of intrapersonal projects, on topics such as overcoming limitations resulting from a disease, starting psychotherapy, enriching their personality, finding out what makes them happy, etc. Only $35 \%$ (35\%) of these types of projects came from participants with high communion. In contrast, females with high communion generated $70 \%$ (70\%) of interpersonal projects, such as being a good role model for a daughter, having a happy family, improving the relationship with their husbands or raising a happy child. Only $30 \%(30 \%)$ of such projects came from highly agentic females.

Further analysis of narratives focused on the way of telling LP stories. Agency appeared to link on one hand with some formal aspects of narratives and on the other hand with the narrative content (the realism of projects). More precisely, females with high agency created relatively shorter, less threaded, more coherent and realistic narratives compared to less agentic females. What is more, their projects had already been implemented or were, at least, in the process of completion. For example:

I have been physically active for some time, for two years. In fact, after long years of sitting at work and, in general, doing nothing, I found that I just need to start moving and it is actually what I keep doing. Now I work on it all the time and already see some positive things, positive changes in myself. (age 40).
At the same time, females with low agency often built inconsistent, multi-threaded (but without any connections between threads) and vague narratives. Less agentic participants tended to fantasise about aims, and often recalled some lists of obstacles with no solutions. Their LPs seemed to be either general or the narrators were uncertain about their completion. One representative of this group said:

Well, I made it up that I get along with pets but I can do something about it. So, I figured out that I would start [a course on] the psychology of animals. But for postgraduate this course is available in [the name of city]. It was also recently opened as a four-year study in [the name of another city], but probably I will not go there. For this study you need to have biological or veterinary studies completed, or at least to be a veterinary technician. (age 24).

Communion was linked to the need for affiliation and the need for other people's presence. Females with high communion generated more saturated projects that included other people, such as doing things together, or simply doing things together as an end in itself (e.g., helping others as the meaning of life). As one participant noted, 'I no longer want to do meaningless accounting work. I definitely want to teach people (age 41).

For comparison, females with low communion generated projects in which other people either did not participate or were instrumentally deployed to provide the operator with a sense of safety or to satisfy the need of relatedness. One participant said:

For me such a big project is my study and the acquisition of competences.... So such a big goal is having abilities and a deep knowledge in the field that interests me. I think that over the years I gradually realise it. (age 29).

\section{Four Ways of Telling Life Project Stories}

To check whether there are some common patterns that differentiate the LPs of females with different levels of maturity, some portraits of the four groups will be presented below.

Life Projects of Low-AG/Low-COM Participants (Low Agency and Low Communion) In this group of $N=13$ participants, LPs were the rarest. Those that we obtained seemed to be general and more akin to a fantasy than a concrete plan. The projects did not usually involve other people directly. They related more to everyday life, so their time perspective was quite short. Moreover, the stories of Low-AG/ Low-COM participants gave the impression of seeking to build their lives from the beginning. Attempts to satisfy some safety needs 
were often present, such as creating safety through building a house or making money (López-Rodríguez \& Hidalgo, 2014). The projects included many actions that were aimed at protection and/or reducing the risk of failure, such as saving money, taking new courses or studying before starting work. A striking characteristic observed here was that Low-AG/Low-COM narrators did not appear to believe that their plans would succeed:

I would like to stop working and just focus on my study at the moment.... But, well, probably I can't stop working now because I have to pay for college. So, one excludes another. So probably I'll work. (age 38). I have to lead this company in order to get money to be able to pursue my hobby. If I have a lot of money, I'll be able to start breeding sport horses. (age 22).

I have got some goals, such as my economic activities. And just thinking about them gives me a sense of safety. Because I think, okay, I have got an idea for myself. But at the same time, sometimes I wonder whether this is nothing more than a self-deception ... to drown out the voice inside my head that is saying, 'You got stuck in your life, and you are doing nothing with it'. (age 28).

Life Projects of Low-AG/High-COM Participants (Low Agency and High Communion) The Low-AG/High-COM group $(N=$ 14) produced lengthy and inconsistent narratives. Their projects were numerous but also vague and uncertain in terms of their realisation. Interpersonal projects appeared to be the most frequent. Although the narratives revealed a kind of balancing between the women's own needs and the needs of other people, the focus was very often on other people, others' issues and problems and less on themselves, their needs, tasks and aims. One Low-AG/High-COM woman said:

I definitely assumed that I would have a happy family and even if it requires a lot of time or an even larger amount of patience from my side, well, I would like to take care of the relationship with my husband because it is important to have a house in the future where the children will feel good. It is all about rearranging priorities and life so as not to get lost in this world, to raise children rather than to out-source it to someone else and pay for it. So, I would like to get a job that is not fully engaging so that I will be able to devote myself to the house and this is my goal for next few years, when I have dealt with my doctorate. (age 30).

Sometimes LPs were called openly by the name of someone else, for example, a 'son project' or 'a husband project':
My family is my project-my husband, actually. Because from the beginning, we have shared responsibilities in this way: He works and brings in money and I do everything else. He is also a little sissy and he comes from a family where his mother and sister cared for the house; his father did not. So, despite his sincere desire to help, he often can't do anything. So, I just have to embrace all matters of life here. And he earns money. So, generally the project is to be pleasant in this regard. (age 30).

Additionally, from the perspective of basic psychological needs, the family context often generated an effort to look for environments that will satisfy both relatedness and competence needs (Ryan \& Deci, 2017), which could also be manifested in focusing on education and family responsibilities. For example:

Well, my LP is precisely studying. I spend a lot of time on it. In general, it costs me a lot to study here because there are a lot of tasks to accomplish, and I have to balance work and family. I also have the dog breeding. It's hard, it's hard for me. But at the same time this is a kind of challenge for me. (age 35).

Low-AG/High-COM try to look for satisfaction of both relatedness and competence needs. The solution is either to balance career (study, work) and family at the same time or to achieve career goals before raising children, which is opposed to Kittrell's (1998) findings.

\section{Life Projects of High-AG/Low-COM Participants (High Agency} and Low Communion) These narratives $(N=14)$ consistently had few threads and contained the continuations of the most important ones. They showed dynamics through the motives of acting and achieving: 'I always strive for my goals even if I happen to fail at the beginning' (age 40); or planning: 'The whole of my life is my project. I like planning and thinking about what to do. For me, the worst situation is when I haven't got a plan' (age 42); or even managing life: 'I organise my life so as not to fall into stagnation. Days fly away and nothing has been achieved. No, life should have its pace' (age 24). The need that most often appeared in LPs of High-AG/Low-COM females was competence (Vansteenkiste et al., 2020). However, an effort to look for both satisfaction of relatedness needs (especially to be needed or to belong to a particular group) and satisfaction of competence needs was also present. Moreover, some fear of not satisfying the need for autonomy was noticeable. One High-AG/ Low-COM woman said:

I want to find a new idea for my professional life, but neither a kind of working in a corporation nor for 
someone else anymore; I'd rather work with someone. I would also like to get to know whether I want to spend the rest of my life with my boyfriend or maybe I am not made for this, and to find out what gives me happiness in my life. I meet the expectations of others perfectly and I would like to find wisdom and knowledge about what I personally want. (age missing).

To some extent, the narrators from High-AG/Low-COM group treated people more instrumentally than those from others. For example, with respect to care in old age, one woman said:

Shortly I will be an old woman, and then what will happen to me? So, my project is to have support from people when I won't be so self-sufficient as I am now, and to give support to others as well. [In terms of not being alone, she said] I would like to have as many people around me as possible, to stay with me. (age 45).

Projects were predominantly intrapersonal. They referred to dealing with their outlook and to self-related attitudes, which included self-improvement and different kinds of individual projects (spiritual, philosophical, coping or adjustment), such as becoming less dependent, finding happiness, 'achieving fulfilment, to be able to say at the end that I do not regret anything in my life' (age 24) and 'development, not necessarily in my professional life, but rather [self-] development in general' (age 37).

\section{Life Projects of High-AG/High-COM Participants (High Agency} and High Communion) In this group $(N=13)$, narratives appeared to be the most coherent and to contain logically continued threads. The projects looked specific, individual and associated with the development of basic psychological needs:

Such a project is my study. I want to finally get what I have not received through all my education, to derive everything that I can from it. It is my development and I want to develop further. It has become so important to me. (age 25).

One High-AG/High-COM woman explained:

At this point of my life, I would like to find some time and, in general, I even manage to do it ... to be able to earn enough money to go back to music ... to play the guitar, to sing, maybe record several songs, to have my own demo. Yes, my most important project now is to go back to music.... It is my passion, an escape from the grey reality and the possibility of fulfilment, to rest from problems, from everything. The moment when I am singing and playing is the moment of forgetting about everything. The music is inside me; it becomes me actually, [and] it defines me in some way. (age 22).

Moreover, other people were present in these projects, but - as often emphasised - in activities which are means to important goals. Hence, for example, helping others is understood here as the mission and the autotelic value: 'To support and to help is the most important goal in my life' (age 44).

The table that summarises these outcomes is presented below (Table 1). From the SDT point of view, the LPs described above are connected with the SDT needs for competence (study, development of skills), autonomy (own decision for finding time for activities) and relatedness (helping others), and as a consequence they are integrated with one's identity_-personal values and goals.

\section{Discussion}

In this study, agency and communion appeared to be uncorrelated. Such a result coincided with that obtained by McAdams et al. (2004), showing that agency and communion are independent dimensions - each with its own correlates. Like men, young females were observed to have stated that career was the most important thing (Levinson, 1986). Indeed, LPs related to studies and work were the most often cited in the general sample of females, regardless of the narrative identity incorporated into the study. Interestingly, no participants realised or intended to pursue a leisure project. Similarly, the health motives hardly ever appeared in the narratives.

However, taking motives of agency and communion separately turned out to show some visible differences within the other types of LPs. Although the narrative identity did not translate into the number of projects, the agentic females generated mostly intrapersonal projects, while those with high communion generated interpersonal ones. These results confirm studies showing that agency relates to personal strivings concerned with being successful, while communion relates to warm and close relationships (McAdams et al., 1996).

Besides the content quality, narrative identity distinguished also some formal aspects of young females' LPs. Particularly, agency was reflected in the way that participants talked about their plans. The LPs of highly agentic females were coherent, which means they had temporally ordered threads, causal relationships between them and continuity. Very often, the female participants with high agency described specific steps that had already been taken and planned. As indicated above, agency is correlated with achievement motivation (McAdams et al., 1996). In turn, the current literature suggests that people characterised by high achievement motivation prefer tasks of intermediate difficulty (Atkinson \& Litwin, 1960), are relatively more endured (Feather, 1961) and future-oriented 
Table 1 Overview of the Main Patterns that Distinguish the Life Projects of Individuals in Groups

\begin{tabular}{lllll}
\hline $\begin{array}{l}\text { Group } \\
\text { Criteria }\end{array}$ & $\begin{array}{l}\text { Low-AG \& } \\
\text { Low-COM }\end{array}$ & $\begin{array}{l}\text { Low-AG \& } \\
\text { High-COM }\end{array}$ & $\begin{array}{l}\text { High-AG \& } \\
\text { Low-COM }\end{array}$ & $\begin{array}{l}\text { High-AG \& } \\
\text { High-COM }\end{array}$ \\
\hline Coherence of narratives & Incoherent & Incoherent & Coherent & Highly coherent \\
Realism of LPs & Fantasies & Unrealistic & Highly realistic & Realistic \\
Distinctive type of LPs & None & Interpersonal & Intrapersonal (improvement) & Intrapersonal (self-development) \\
Dominant need & Safety & Relatedness & Competence & Self-development \\
Type of conflict & Dreams vs. obstacles & Own needs vs. others' needs & Relatedness vs. autonomy & None \\
\hline
\end{tabular}

Note. $\mathrm{LPs}=$ life projects, $\mathrm{AG}=$ agency, $\mathrm{COM}=$ communion

(McClelland, 1961). It can therefore be concluded that LPs of highly agentic females are more likely to be implemented through the mechanism of motivation. Studies suggest that the challenges of intermediate difficulty (optimal challenges) are positively related to the success of their realisation and performance (Akizuki \& Ohashi, 2015; Orvis et al., 2008). In turn, females with low agency preferred to fantasise about the future. Their LPs contained many, but mutually exclusive, threads or abounded in potential obstacles on their way to the goal. Referring to the construct of integrative complexity (Suedfeld \& Tetlock, 2001), the narratives about LPs of low agentic females were characterized by high differentiation and low integration. As a result, LPs of low agentic young females might be difficult or impossible to finish.

The adoption of the personal identity development construct (Erikson, 1950; Labouvie-Vief, 1994) has enabled the emergence of further phenomena. Separating the levels of personality development turned out to reveal the meaning that a given project had for females. It also exposed some of their dominant needs as well as internal conflicts. What is interesting is that identity development phases were unrelated to age in the sample of adult females. It might suggest that it is not the age per se but rather the challenges and life endeavors that we take up that over time translate into personality development. Without life projects, we can still remain the same people, no matter how much time passes. It means that the strategy of postponing life goals until we feel mature enough to pursue them may not always be effective. Conversely, we develop through our involvement in life projects even though we might be not ready for them.

Life projects of participants with not-yet developed identity (Low-AG/Low-COM) were focused mainly on safety needs (López-Rodríguez \& Hidalgo, 2014). In addition, they were relatively rare, non-specific and more like 'having your head in the clouds' than concrete, realistic projects. Even the narrators did not appear to believe that their plans would succeed. One possible explanation is that maintenance factors (relating to physiological and safety needs), connected with a low identity development phase, are less motivating than factors relating to higher level needs, especially ego needs (Herzberg,
1964). At the same time, there is evidence that projects that are goal-directed shape identity (Christiansen, 2011; Ryan \& Deci, 2017). If there are no such projects, personality cannot develop. It suggests the existence of some kind of feedback loop, whereby immature identity may prevent individuals from generating and completing LPs; this may, in turn, inhibit further identity development. This interpretation could also be applied to our results.

Identity with one dominating motive of either agency or communion (semi-mature) was associated with intrapersonal or interpersonal projects, respectively. Furthermore, the narratives created in these two subgroups referred to competence and relatedness needs of self-determination theory. There were some conflicts in decisions whether to focus on environments that satisfy relatedness or autonomy needs, and satisfaction of their own needs and other people's needs. The set of narrative properties (Low-AG/High-COM or High-AG/Low$\mathrm{COM}$ ) did not necessarily prove to clearly determine how the conflict was resolved. Rather, it was associated with the recall of specific types of needs. However, both needs were still active or constituted a background. What is more, the competitiveness of the needs with limited possibilities of implementation systematically revealed some tensions. This subgroup seems to resemble a young adult entangled in what could be called 'Levinson's trap of contradiction between internal conflicts and external demands'.

Surprisingly, the fully developed identity with strong motives of both agency and communion did not show any conflicts. The character of intrapersonal projects dominating in this group, differed from the improvement of competencies or better coping that was often reported among females from the group of High-AG/Low-COM. It was rather about selfdevelopment, which in SDT means striving to satisfy the need for competence. The referenced projects had the status of goals in themselves and did not lead to any other purposes. Other people were present in the projects as co-beneficiaries, not as means to a goal, as happened in the group of High-AG/ Low-COM. Interestingly, no conflicts were associated with their presence. It may suggest that the transition from semimature to fully developed identity assumes success in solving 
the aforementioned conflicts and integrating a positive flow from agency (realistic intrapersonal goals) and communion (goals assuming the presence and participation of other people) at the same time.

Some limitations require consideration when interpreting these findings. First, the results are limited to Caucasian females, which were recruited among students, and may not be broadly generalised to other populations. However, although student samples are not considered as representative samples for the general population, some research suggests that the differences between student and non-student samples are not so significant (Wheeler et al., 2014).

In conclusion, given these limitations, the present study empirically shows that in addition to predominant study and career projects, females implement LPs that are consistent with their narrative identity. This internalized and evolving story of the self that is built by the person to make meaning out of her life translates not only into the category but also the reality of the LPs. It suggests ways of overcoming developmental dilemmas through solving internal conflicts and then, as a consequence, relating to the enhanced psychological maturity. At the same time, through reciprocal linking, the psychological maturity relevant to the identity development stages affects the way LPs are created, reported and implemented.

The identification of the significance of both agency and communion, and of their dialectical mutual enhancement in normal development, can provide a theoretical basis for counselling how to resolve internal conflicts resulting from the period of early adulthood, and for appreciating and encouraging the development of these essential dimensions in young females.

Availability of Data and Material The data for this study can be found on the Open Science Foundation (https://osf.io//XXXX).

\section{Code Availability MAXQDA 2020 and IBM SPSS Statistics 26.}

Funding The presented study was supported by the grant 2013/10/E/ HS6/00502 from the National Science Center, Poland, awarded to the fourth author.

\section{Declarations}

Ethical Statement The project was approved by the Academic Human Research Ethics Committee.

Informed Consent Interested volunteers were informed about the nature and purpose of the study and offered the opportunity to participate. When they chose to participate, they were informed that they could discontinue at any time and their responses would be confidential and not revealed to anyone.

Conflicts of Interest/Competing Interests We have no conflicts of interest to disclose.
Open Access This article is licensed under a Creative Commons Attribution 4.0 International License, which permits use, sharing, adaptation, distribution and reproduction in any medium or format, as long as you give appropriate credit to the original author(s) and the source, provide a link to the Creative Commons licence, and indicate if changes were made. The images or other third party material in this article are included in the article's Creative Commons licence, unless indicated otherwise in a credit line to the material. If material is not included in the article's Creative Commons licence and your intended use is not permitted by statutory regulation or exceeds the permitted use, you will need to obtain permission directly from the copyright holder. To view a copy of this licence, visit http://creativecommons.org/licenses/by/4.0/.

\section{References}

Akizuki, K., \& Ohashi, Y. (2015). Measurement of functional task difficulty during motor learning: What level of difficulty corresponds to the optimal challenge point? Human Movement Science, 43, 107117. https://doi.org/10.1016/j.humov.2015.07.007.

Atkinson, J. W., \& Litwin, G. H. (1960). Achievement motive and test anxiety conceived as motive to approach success and motive to avoid failure. Journal of Abnormal and Social Psychology, 60, 52-63. https://doi.org/10.1037/h0041119.

Bakan, D. (1966). The duality of human existence: Isolation and communion in Western man. Rand McNally.

Bauer, J. J., McAdams, D. P., \& Pals, J. L. (2006). Narrative identity and eudaimonic well-being. Journal of Happiness Studies, 9, 81-104. https://doi.org/10.1007/s10902-006-9021-6.

Braun, V., \& Clarke, V. (2006). Using thematic analysis in psychology. Qualitative Research in Psychology, 3(2), 77-101. https://doi.org/ 10.1191/1478088706qp063oa.

Christiansen, C. (2011). Identity, personal projects and happiness: Self construction in everyday action. Journal of Occupational Science, 7(3), 98-107. https://doi.org/10.1080/14427591.2000.9686472.

Cicchetti, D. V. (1994). Guidelines, criteria, and rules of thumb for evaluating normed and standardized assessment instruments in psychology. Psychological Assessment, 6(4), 284-290. https://doi.org/10. 1037/1040-3590.6.4.284.

Deci, E. L., \& Ryan, R. M. (2000). The "what" and "why" of goal pursuits: Human needs and the self-determination of behavior. Psychological Inquiry, 11(4), 227-268.

Erikson, E. H. (1950). Childhood and society. Norton.

Erikson, E. H. (1968). Identity, youth and crisis. Norton.

Feather, N. T. (1961). The relationship of persistence at a task to expectation of success and achievement related motives. Journal of Abnormal and Social Psychology, 63, 552-561.

Guisinger, S., \& Blatt, S. (1994). Individuality and relatedness. American Psychologist, 49, 104-111. https://doi.org/10.1037/0003-066X.49. 2.104.

Gutmann, D. (1994). Reclaimed powers: Men and women in later life. Northwestern University Press.

Herzberg, F. (1964). The motivation-hygiene concept and problems of manpower. Personnel Administrator, 27, 3-7.

Kittrell, D. (1998). A comparison of the evolution of men's and women's dreams in Daniel Levinson's theory of adult development. Journal of Adult Development, 5(2), 105-115. https://doi.org/10.1023/A: 1023039611468.

Labouvie-Vief, G. (1994). Psyche and Eros: Mind and gender in the life course. Cambridge University Press.

Lapsley, D., \& Hardy, S. A. (2017). Identity formation and moral development in emerging adulthood. In L. Padilla-Walker, \& L. J. Nelson 
(Eds.) Flourishing in emerging adulthood: Positive development during the third decade of life (pp. 14-39). Oxford University Press. Levinson, D. J. (1978). The seasons of a man's life. Alfred Knopf.

Levinson, D. J. (1986). A conception of adult development. American Psychologist, 41, 3-13.

Levinson, D. J. (1996). The seasons of a woman's life. Alfred Knopf.

Linde, C. (1993). Life stories: The creation of coherence. Oxford University Press.

Little, B. R., \& Gee, T. L. (2007). The methodology of personal projects analysis: Four modules and a funnel. In B. R. Little, K. Salmela-Aro, \& S. D. Phillips (Eds.), Personal project pursuit: Goals, action, and human flourishing (pp. 51-94). Mahwah: Lawrence Erlbaum Associates Publishers.

Lodi-Smith, J., Geise, A. C., Roberts, B. W., \& Robins, R. W. (2009). Narrating personality change. Journal of Personality and Social Psychology, 96, 679-689. https://doi.org/10.1037/a0014611.

López-Rodríguez, V. A., \& Hidalgo, A. (2014). Security needs: Some considerations about its integration into the self-determination theory (SDT). Dirección y Organización, 52, 46-58.

McAdams, D. P. (2001). The psychology of life stories. Review of General Psychology, 5, 100-122. https://doi.org/10.1037/10892680.5.2.100

McAdams, D. P. (2002). Coding systems for themes of agency and communion. Retrieved March 08, 2016, from http://www.sesp. northwestern.edu/foley/instruments/agency

McAdams, D. P. (2008a). The life story interview. Retrieved March 08, 2016, from http://www.sesp.northwestern.edu/foley/instruments/ interview/

McAdams, D. P. (2008b). Personal narratives and the life story. In O. P. John, R. W. Robins, \& L. A. Pervin (Eds.), Handbook of personality: Theory and research (pp. 242-262). New York: Guilford Press.

McAdams, D. P., \& McLean, K. C. (2013). Narrative identity. Current Directions in Psychological Science, 22(3), 233-238. https://doi. org/10.1177/0963721413475622.

McAdams, D. P., Hoffman, B. J., Mansfield, E. D., \& Day, R. (1996). Themes of agency and communion in significant autobiographical scenes. Journal of Personality, 64, 339-378. https://doi.org/10. 1111/j.1467-6494.1996.tb00514.x.

McAdams, D. P., \& Pals, J. L. (2006). A new big five: Fundamental principles for an integrative science of personality. American Psychologist, 61, 204-217. https://doi.org/10.1037/0003-066X.61. 3.204.

McAdams, D. P., Anyidoho, N. A., Brown, C., Huang, Y. T., Kaplan, B., \& Machado, M. A. (2004). Traits and stories: Links between dispositional and narrative features of personality. Journal of Personality, 72(4), 761-784. https://doi.org/10.1111/j.0022-3506.2004.00279.x.

McClelland, D. C. (1961). The achieving society. Van Nostrand.

McGregor, I., \& Little, B. R. (1998). Personal projects, happiness, and meaning: On doing well and being yourself. Journal of Personality and Social Psychology, 74(2), 494-512. https://doi.org/10.1037/ 0022-3514.74.2.494.
McGregor, I., McAdams, D. P., \& Little, B. R. (2006). Personal projects, life stories, and happiness: On being true to traits. Journal of Research in Personality, 40(5), 551-572. https://doi.org/10.1016/j. jrp.2005.05.002.

Moskal, M. (2020). Gendered differences in international graduates' mobility, identity and career development. Social \& Cultural Geography, 21(3), 421-440.

Orwin, R. G. (1994) Evaluating coding decisions. In H. Cooper and L. V. Hedges (Eds.), The Handbook of Research Synthesis (pp. 150-151). Russell Sage Foundation.

Orvis, K. A., Horn, D. B., \& Belanich, J. (2008). The roles of task difficulty and prior videogame experience on performance and motivation in instructional videogames. Computers in Human Behavior, 24(5), 2415-2433.

Ryan, R. M., \& Deci, E. L. (2017). Self-determination theory: Basic psychological needs in motivation, development, and wellness. Guilford Press.

Schwartz, S. J. (2001). The evolution of Eriksonian and neo-Eriksonian identity theory and research: A review and integration. Identity: An International Journal of Theory and Research, 1, 7-58. https://doi. org/10.1207/S1532706XSCHWARTZ.

Shrout, P. E., \& Fleiss, J. L. (1979). Intraclass correlations: Uses in assessing rater reliability. Psychological Bulletin, 86, 420-428. https://doi.org/10.1037/0033-2909.86.2.420.

Suedfeld, P., \& Tetlock, P. E. (2001). Individual differences in information processing. In A. Tesser and N. Schwarz (Eds.), Blackwell Handbook of Social Psychology: Intraindividual Processes (pp. 284-304). Blackwell Publishers.

Taylor, J. M., Gilligan, C., \& Sullivan, A. M. (1996). Missing voices, changing meanings: Developing a voice-centered, relational method, and an interpretive community. In S. Wilkinson (Ed.), Feminist social psychologies. International perspectives (pp. 233-257). Buckingham: Open University Press.

Turner, J. S., \& Helms, D. B. (1995). Lifespan development (5th ed.) Harcourt Brace College Publishers.

Vansteenkiste, M., Ryan, R. M., \& Soenens, B. (2020). Basic psychological need theory: Advancements, critical themes, and future directions. Motivation \& Emotions, 44, 1-31. https://doi.org/10.1007/ s11031-019-09818-1.

Wheeler, A. R., Shanine, K. K., Leon, M. R., \& Whitman, M. V. (2014). Student-recruited samples in organizational research: A review, analysis, and guidelines for future research. Journal of Occupational and Organizational Psychology, 87, 1-26. https:// doi.org/10.1111/joop.12042.

Woike, B. (1995). Most memorable experiences: Evidence for a link between implicit and explicit motives and social cognitive processes in everyday life. Journal of Personality and Social Psychology, 68, 1081-1091. https://doi.org/10.1037/0022-3514.68.6.1081.

Publisher's Note Springer Nature remains neutral with regard to jurisdictional claims in published maps and institutional affiliations. 